\title{
Design of Carborane Molecular Architectures via Electronic Structure Computations
}

\author{
Josep M. Oliva, ${ }^{1}$ Luis Serrano-Andrés, ${ }^{2}$ Douglas J. Klein, ${ }^{3}$ \\ Paul von Ragué Schleyer, ${ }^{4}$ and Josef Michl $^{5}$ \\ ${ }^{1}$ Department of Structure, Energy and Chemical Reactivity, Instituto de Química-Física Rocasolano_CSIC, 28006 Madrid, Spain \\ ${ }^{2}$ Institut de Ciència Molecular, Universitat de València, 46071 Valencia, Spain \\ ${ }^{3}$ Department of Marine Sciences, Texas A\&M University at Galveston, Galveston, TX 77553-1675, USA \\ ${ }^{4}$ Center for Computational Chemistry, Department of Chemistry, University of Georgia, Athens, GA 30602, USA \\ ${ }^{5}$ Institute of Organic Chemistry and Biochemistry, Academy of Sciences of the Czech Republic, 16610 Prague 6, Czech Republic
}

Correspondence should be addressed to Josep M. Oliva, j.m.oliva@iqfr.csic.es

Received 12 June 2009; Accepted 24 September 2009

Recommended by Mark van Der Auweraer

Quantum-mechanical electronic structure computations were employed to explore initial steps towards a comprehensive design of polycarborane architectures through assembly of molecular units. Aspects considered were (i) the striking modification of geometrical parameters through substitution, (ii) endohedral carboranes and proposed ejection mechanisms for energy/ion/atom/energy storage/transport, (iii) the excited state character in single and dimeric molecular units, and (iv) higher architectural constructs. A goal of this work is to find optimal architectures where atom/ion/energy/spin transport within carborane superclusters is feasible in order to modernize and improve future photoenergy processes.

Copyright (C) 2009 Josep M. Oliva et al. This is an open access article distributed under the Creative Commons Attribution License, which permits unrestricted use, distribution, and reproduction in any medium, provided the original work is properly cited.

\section{Introduction}

The number of new borane and carborane molecules and their crystal structures has increased enormously due to the rich variety of synthetic routes discovered in the last decades $[1,2]$. We have utilized a bottom-totop approach and electronic structure computations to design icosahedral borane and carborane molecular architectures by starting with single molecules as well as with dimeric units connected directly or through bridges [3-16]. Knowledge of the electronic, magnetic, optical, and other properties of such single and dimeric units illuminates the evaluation of the global properties of $1 \mathrm{D}, 2 \mathrm{D}$, or $3 \mathrm{D}$ superclusters and nanostructures [17-22]. The use of light to modify properties of nanostructures is at the heart of current cutting-edge technology. Thus, the irradiation of photonic crystals can change their conducting properties [23] and control spin transport. [24, 25] We now use electronic structure computations to explore the first design stages of carborane-based architectures having potential uses in molecular and nano-photochemistry.

\section{Computational Methodology}

For the computations of the electronic structure in the compounds studied in this work, we employed different methods. As a benchmark for triplet and other excited states, we used the complete active space self-consistent field (CASSCF) [26] and their perturbative methods (CASPT2) [27], as implemented in the MOLCAS [28] program. For the optimization of geometries in the groundstate and triplet states, use was made of the well-known B3LYP hybrid which combines Hartree-Fock and density functional theory [29-31] as implemented in the Gaussian03 program [32]. The Becke, three-parameter, Lee-Yang-Parr (B3LYP) hybrid exchange-correlation $(x c)$ functional is constructed as a linear combination of the Hartree-Fock exact exchange functional $\left(E_{x}^{\mathrm{HF}}\right)$ and a given number of exchange and 


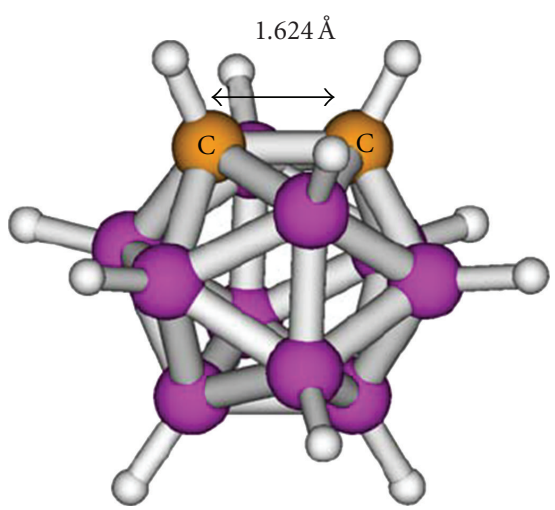

(a)

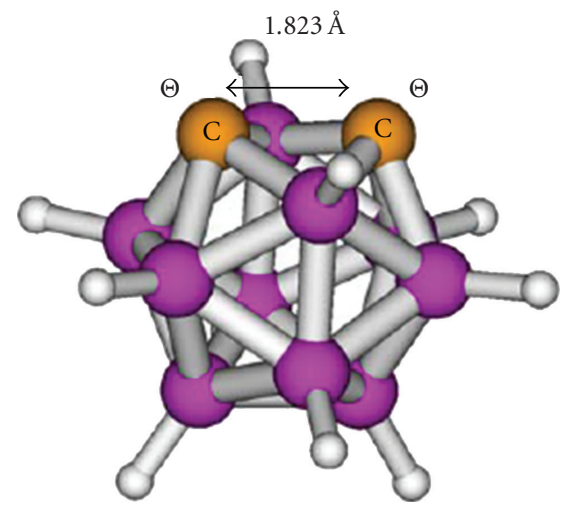

(c)

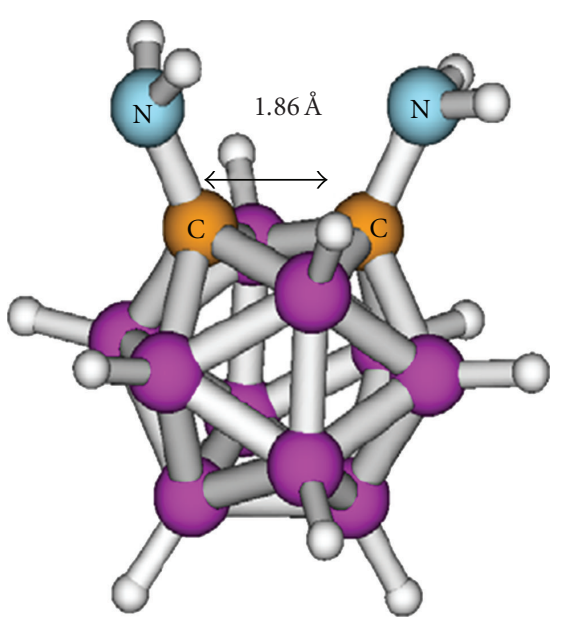

(b)

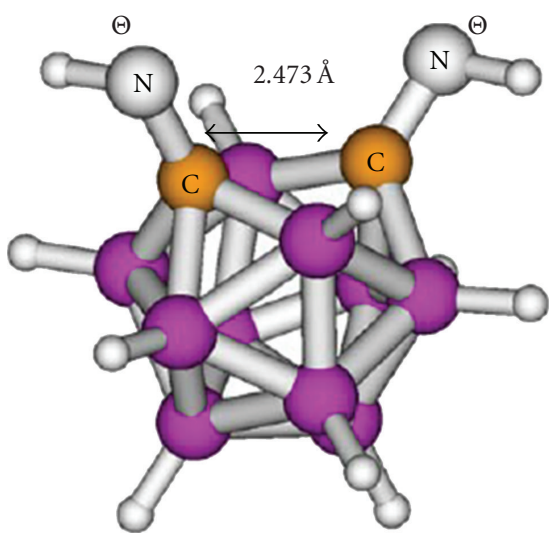

(d)

FIGURE 1: Optimized geometry of singlet ground states (total spin $S=0$ ): (a) $1,2-\mathrm{C}_{2} \mathrm{~B}_{10} \mathrm{H}_{12}, \quad(\mathrm{~b}) 1,2-\left(\mathrm{NH}_{2}\right)_{2}-1,2-\mathrm{C}_{2} \mathrm{~B}_{10} \mathrm{H}_{10}, \quad(\mathrm{c})$ $\left[1,2-\mathrm{C}_{2} \mathrm{~B}_{10} \mathrm{H}_{10}\right]^{2-}$, and (d) $1,2-\left(\mathrm{NH}^{-}\right)_{2}-1,2-\mathrm{C}_{2} \mathrm{~B}_{10} \mathrm{H}_{10}$. Computations are carried out with the B3LYP/6-31G* model. All geometries correspond to energy minima.

correlation explicit density functionals ( $x$ and $c$ as subindex correspond to exchange and correlation respectively): $E_{x c}^{\mathrm{B} 3 \mathrm{LYP}}$ $=E_{x c}^{\mathrm{LDA}}+0.20\left\{E_{x}^{\mathrm{HF}}-E_{x}^{\mathrm{LDA}}\right\}+0.72\left\{E_{x}^{\mathrm{GGA}}-E_{x}^{\mathrm{LDA}}\right\}+$ $0.81\left\{E_{c}^{\mathrm{GGA}}-E_{c}^{\mathrm{LDA}}\right\}$, where LDA and GGA stand for local density approximation and generalized gradient approximation. As regards to the computation of singlet-triplet energy gaps in the biradicals presented in this work, we used the CASSSCF/CASPT2 method as benchmark model-the multireference wave functions being based on an active space of six electrons distributed in six molecular orbitals $(6,6)$ - together with the broken-symmetry (U)B3LYP [3335] approach: in the latter, the singlet-triplet energy gaps are estimated as $\Delta E_{\mathrm{BS}}=2\left(E_{\mathrm{BS}}-E_{T}\right) /\left(\left\langle\hat{S}^{2}\right\rangle_{T}-\left\langle\hat{S}^{2}\right\rangle_{\mathrm{BS}}\right)$, where $E_{\mathrm{BS}}, E_{T},\left\langle\hat{S}^{2}\right\rangle_{\mathrm{BS}}$, and $\left\langle\hat{S}^{2}\right\rangle_{T}$ stand for energy of the brokensymmetry solution, energy of the triplet state, and expectation value of $\hat{S}^{2}$ (square of spin operator) for the brokensymmetry and triplet states, respectively. In all studies we have used the $6-31 G^{*}$ and $6-31+G^{*}$ basis sets, which are of double-zeta quality and contain polarization functions for all nonhydrogen atoms $\left(6-31 \mathrm{G}^{*}\right)$ and polarization plus diffuse functions for all nonhydrogen atoms $\left(6-31+\mathrm{G}^{*}\right)$ respectively. Larger basis sets have been used when necessary for checking the validity and accuracy of the computed properties.

\section{Results and Discussion}

A goal in the nanoscience of $n \mathrm{D}$-dimensional $(n=$ $\{1,2,3\}$ ) networks made up of single 0D units (molecules/clusters/atoms/ions) is to ascertain the global or local properties of the system as function of the building units. What changes or modifications result from external perturbations (e.g., a electromagnetic field)? If a single unit can be modified, to what extent do the properties of a network built from such units change, if at all? We have addressed such questions by starting with the wellknown basic icosahedral ortho, meta, and para carborane as well as borane $\mathrm{B}_{12} \mathrm{H}_{12}{ }^{2-}$ units [36] to construct $n \mathrm{D}$ 


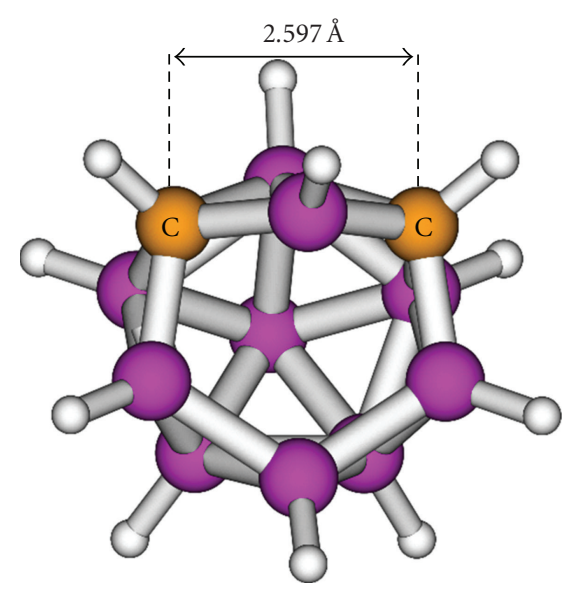

(a)

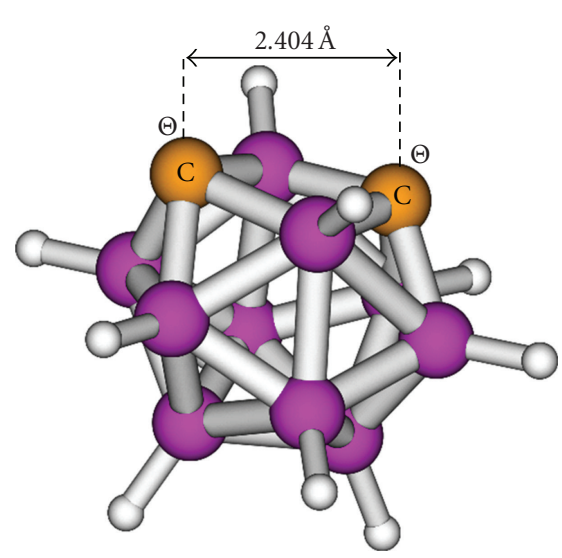

(c)

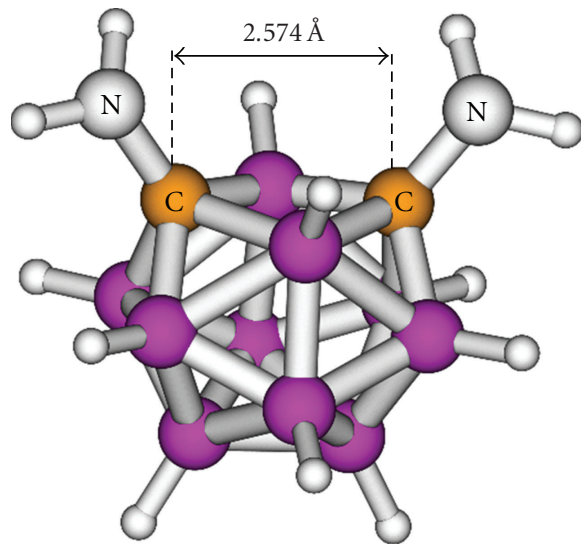

(b)

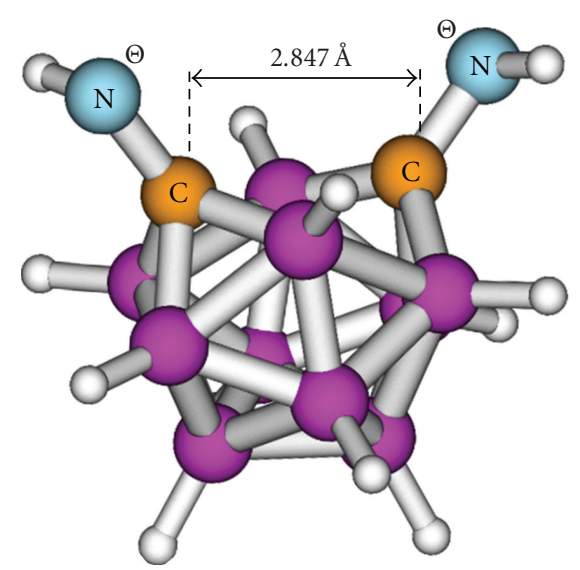

(d)

Figure 2: Optimized geometry of triplet states (total spin $\mathrm{S}=1$ ): (a) $1,2-\mathrm{C}_{2} \mathrm{~B}_{10} \mathrm{H}_{12}$, (b) 1,2- $\left(\mathrm{NH}_{2}\right)_{2}-1,2-\mathrm{C}_{2} \mathrm{~B}_{10} \mathrm{H}_{10}$, (c) $\left[1,2-\mathrm{C}_{2} \mathrm{~B}_{10} \mathrm{H}_{10}\right]^{2-}$, and (d) 1,2-( $\left.\mathrm{NH}^{-}\right)_{2}-1,2-\mathrm{C}_{2} \mathrm{~B}_{10} \mathrm{H}_{10}$. Computations are carried out with the UB3LYP/6-31G* model. All geometries correspond to energy minima.

dimensional networks and to explore their properties [18, 19, 37-40]. While these compounds have been known since the 1960s, the properties of $n \mathrm{D}$ dimensional networks made up thereof are less known. This section describes the changes in geometric and electronic properties, $P$, that these systems undergo as a function of substituents $R$, charges $q$, spins $S$, and the nature of the wave functions $\Psi$, and thus $P=P(q, S, R, \Psi)$. We also consider endohedral and dimeric structures connected directly or with bridging units.

We have established that striking variations (over $1 \AA$ !) in cage carbon-carbon distances $\left(C_{c} \cdots C_{c}\right)$ occur in $1,2-$ disubtituted $o$-carboranes and in the corresponding dianions (formed formally by double proton abstraction) [8]. Figure 1 shows $C_{c} \cdots C_{c}$ distances ranging from $1.6 \AA$ to $2.5 \AA$ as a function of charge and substituent; the B3LYP/6-31G* model was used in the computations. Here we should emphasize that the feeding of electronic charge into the cage causes a gradual transformation from a closo toward a nido, arachno, or hypho type of geometrical structure [41]. The triplet states of such systems [9] (see Figure 2) also reveal rich structural variety.

Figure 2 shows the optimized geometries of the triplet states of the same $o$-carboranes and the dianions considered in Figure 1 as singlet ground states; Figure 3 displays the corresponding spin density. The triplet states display interesting distortions and geometrical arrangements: for instance, a hexagonal window appears in the triplet state geometry of $o$-carborane (Figure 2(a)) and the $C_{c} \cdots C_{c}$ distance has increased by $\approx 1 \AA$ ! The amino groups in triplet $1,2-\left(\mathrm{NH}_{2}\right)_{2}$ $1,2-\mathrm{C}_{2} \mathrm{~B}_{10} \mathrm{H}_{12}$ are essentially planar (Figure 2(b)) and the $C_{c} \cdots C_{c}$ distance has increased by $\approx 0.7 \AA$. After double proton abstraction, the $C_{c} \cdots C_{c}$ distances of the triplet dianions (Figures 2(c) and 2(d)) remain similar for $o$ carborane but increase up to $2.85 \AA$ in the $1,2-\left(\mathrm{NH}^{-}\right)_{2}-1,2-$ $\mathrm{C}_{2} \mathrm{~B}_{10} \mathrm{H}_{12}$ triplet state geometry (Figure $2(\mathrm{~d})$ ).

The spin density (Figure 3 ) in these clusters is concentrated mainly around the exo groups $\mathrm{NH}_{2}$ an $\mathrm{NH}^{-}$and on 


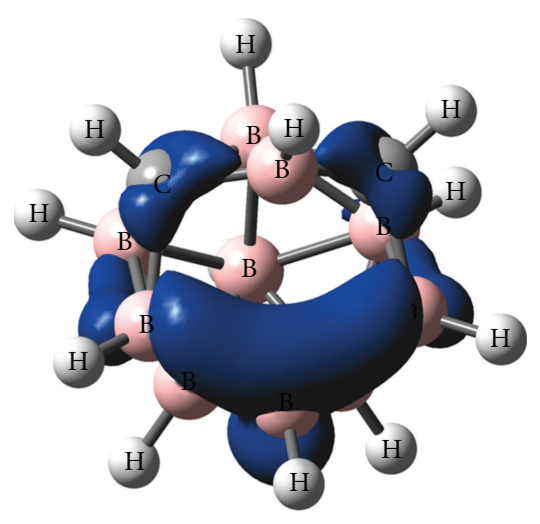

(a)

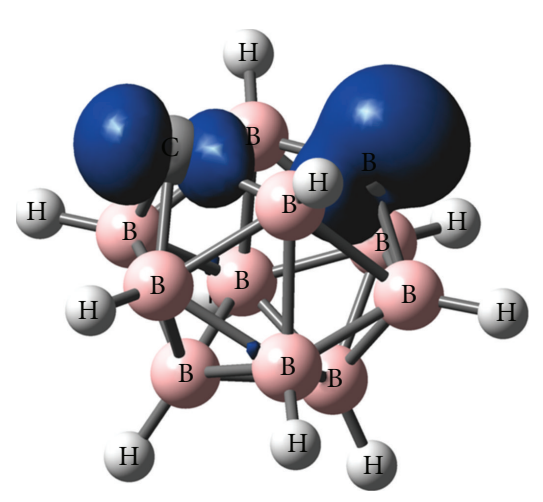

(c)

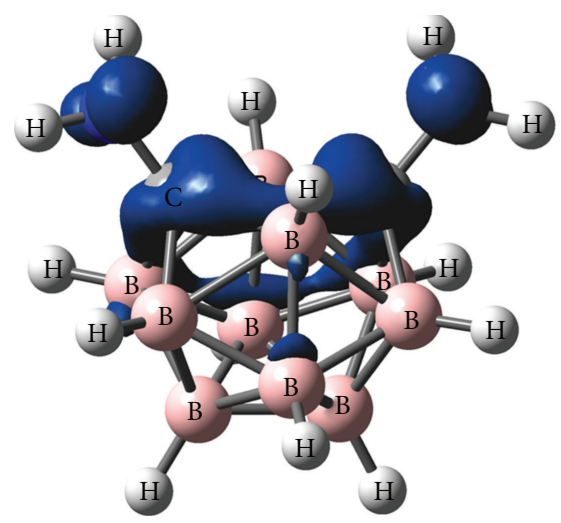

(b)

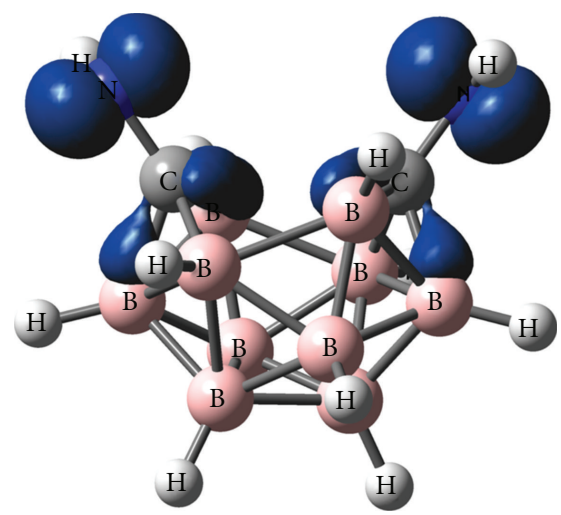

(d)

Figure 3: Spin densities $\rho_{s}^{T}$ (isovalue $= \pm 0.01$ ) for the triplet states (total spin $S=1$ ) of carborane clusters from Figure 2. (a) $\rho_{s}^{T}\{1,2-$ $\left.\mathrm{C}_{2} \mathrm{~B}_{10} \mathrm{H}_{12}\right\}$, (b) $\rho_{s}^{T}\left\{1,2-\left(\mathrm{NH}_{2}\right)_{2}-1,2-\mathrm{C}_{2} \mathrm{~B}_{10} \mathrm{H}_{10}\right\}$, (c) $\rho_{s}^{T}\left\{\left[1,2-\mathrm{C}_{2} \mathrm{~B}_{10} \mathrm{H}_{10}\right]^{2-}\right\}$, and (d) $\rho_{s}^{T}\left\{1,2-\left(\mathrm{NH}^{-}\right)_{2}-1,2-\mathrm{C}_{2} \mathrm{~B}_{10} \mathrm{H}_{10}\right\}$. Computations are carried out with the UB3LYP/6-31G* model.

the cage carbon atoms. For $o$-carborane (Figure 2(a)), the spin density is spread around the "open" frontal hexagonal window (Figure 3(a)).

With respect to electronic structure properties, results of a comprehensive study [9] of the adiabatic singlettriplet energy gaps- $-\Delta E_{S T}=\left(E_{T}^{\text {opt }}-E_{S}^{\text {opt }}\right)$-in a series of substituted $o$-carboranes are plotted in Figure 4. The adiabatic singlet-triplet energy gap is computed as the energy difference between the triplet and the singlet state optimized geometries: $\Delta E_{\mathrm{ST}}=\left(E_{T}^{\mathrm{opt}}-E_{S}^{\mathrm{opt}}\right)$. For the results displayed in Figure 4, computations at the (U)B3LYP/6-31G* level of theory were used, the latter calibrated with the more accurate CASPT2 method. As some of the gaps are within the visible region of the electromagnetic spectrum, the corresponding systems should display photochemical absorption/emission properties, if intersystem crossing processes are plausible [42].

Inserting endohedral atoms/ions inside the carborane cage is another possibility for changing the properties of the single units forming the $n \mathrm{D}$ networks $[10-12,43,44]$. Although endohedral carboranes have not been realized experimentally, recent computational studies suggest than an insertion/ejection mechanism should be plausible using photon energies around $6.4 \mathrm{eV}$ for $\mathrm{Li}^{+}$and $\mathrm{CB}_{11} \mathrm{H}_{12}{ }^{-}[10]$ (see Figure 5).

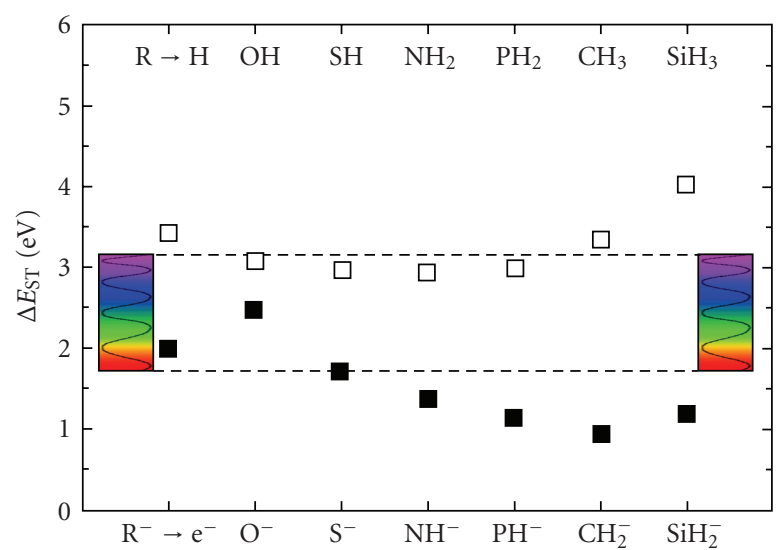

FIGURE 4: Adiabatic singlet-triplet energy gaps (in $\mathrm{eV}$ ) for a series of 1,2-disubstituted icosahedral $o$-carboranes and their dianions after double proton abstraction. Empty and full squares correspond, respectively, to adiabatic singlet-triplet energy gaps in neutral-1,2(R) ${ }_{2}-1,2-\mathrm{C}_{2} \mathrm{~B}_{10} \mathrm{H}_{10}$ - and the corresponding dianionic carborane1,2- $\left(\mathrm{R}^{-}\right)_{2}-1,2-\mathrm{C}_{2} \mathrm{~B}_{10} \mathrm{H}_{10}$-after double proton abstraction. All computations carried out with the (U)B3LYP/6-31G* method.

The implementation of ejection mechanisms similar to that shown in Figure 5, in an $n \mathrm{D}$-dimensional carborane 


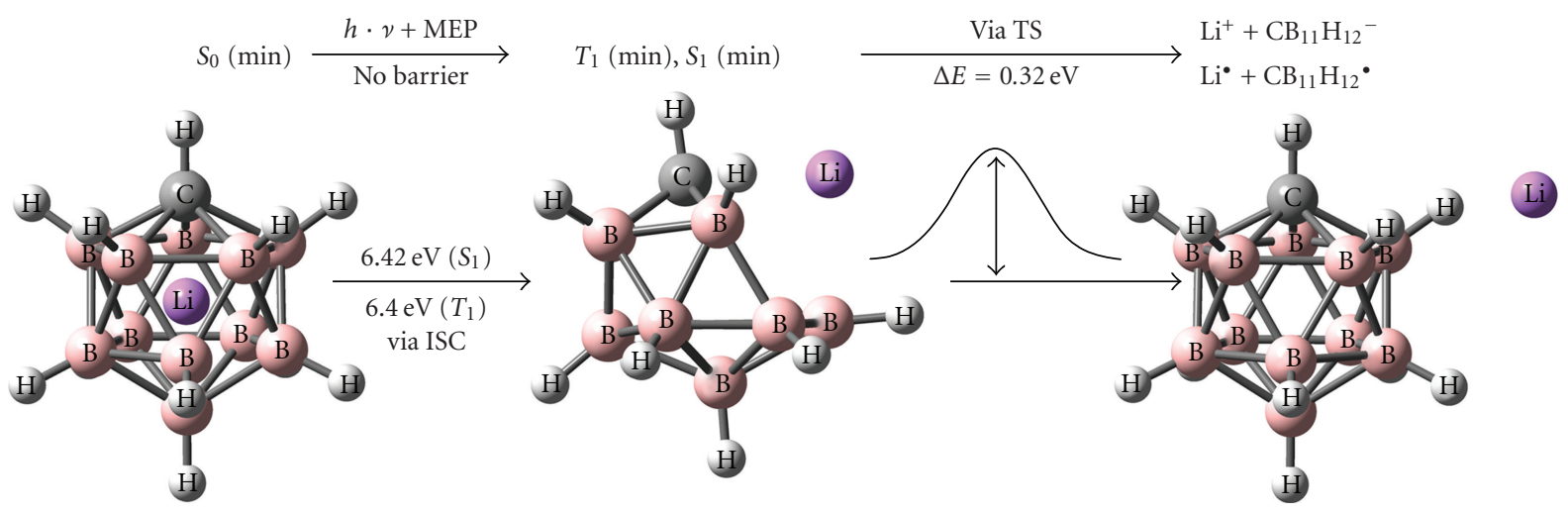

FIGURE 5: Photochemical evolution of the endohedral $\mathrm{Li}_{0} \mathrm{CB}_{11} \mathrm{H}_{12}$ carborane complex upon absorption of radiation leading to a selective release of the inner atom. The scheme is based on quantum chemical CASPT2//DFT/B3LYP and CASPT2//CASSCF calculations, the latter with an active space of two electrons in two orbitals; larger active spaces lead practically to same results [10]. ISC: intersystem crossing.

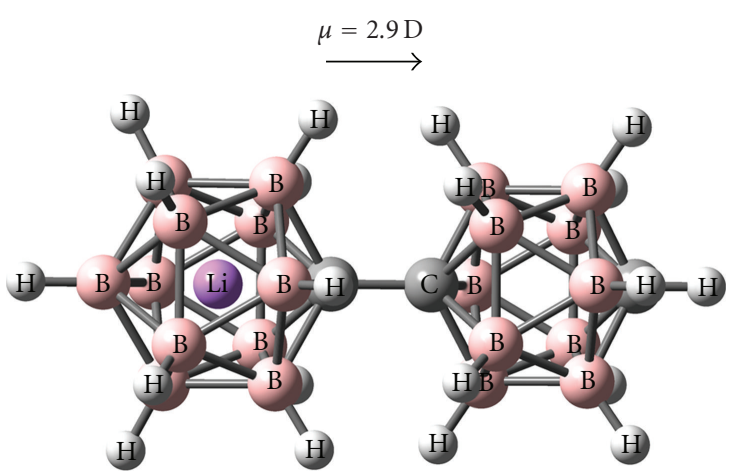

(a)

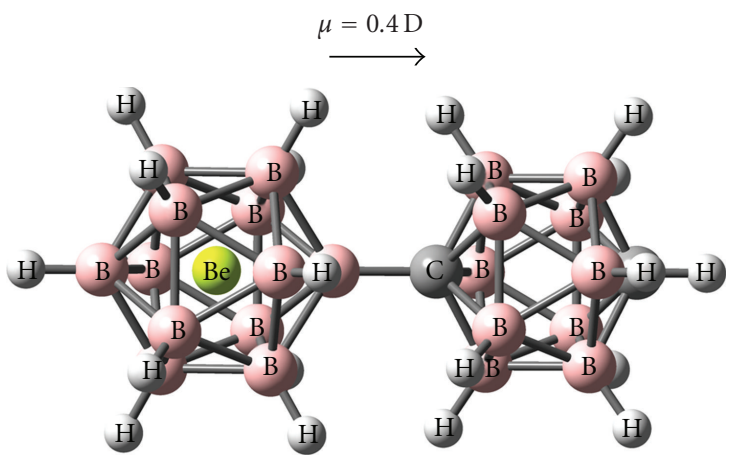

(c)

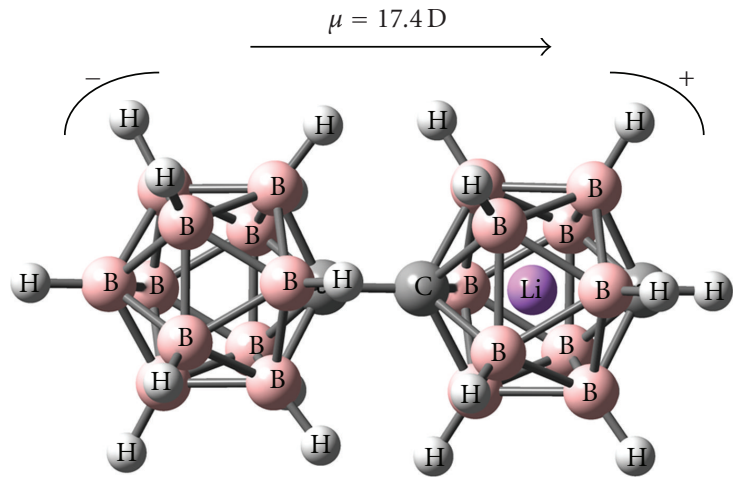

(b)

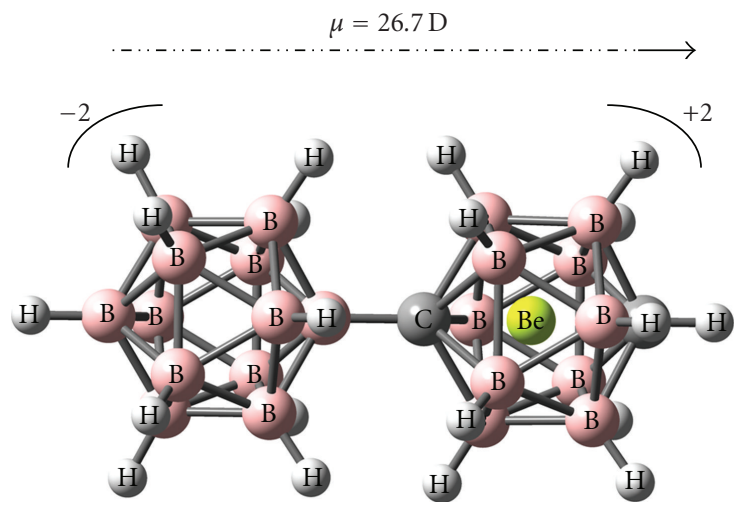

(d)

FIGURE 6: Dimeric carborane systems combining neutral $p$-carborane and $\mathrm{CB}_{11} \mathrm{H}_{12}{ }^{-}$or $\mathrm{B}_{12} \mathrm{H}_{12}{ }^{2-}$ units, connected through $\mathrm{C}-\mathrm{C}$ and $\mathrm{C}-$ B bonds, respectively. Dipole moments (in Debye) are computed at the B3LYP/6-31G* level of theory. (a) $\left\{\mathrm{Li} @ \mathrm{CB}_{11} \mathrm{H}_{11}\right\}-\left\{p-\mathrm{C}_{2} \mathrm{~B}_{10} \mathrm{H}_{11}\right\}$, (b) $\left\{\mathrm{CB}_{11} \mathrm{H}_{11}\right\}-\left\{\mathrm{Li} @ p-\mathrm{C}_{2} \mathrm{~B}_{10} \mathrm{H}_{11}\right\}$, (c) $\left\{\mathrm{Be} @ \mathrm{~B}_{12} \mathrm{H}_{11}\right\}-\left\{p-\mathrm{C}_{2} \mathrm{~B}_{10} \mathrm{H}_{11}\right\}$, and (d) $\left\{\mathrm{B}_{12} \mathrm{H}_{11}\right\}-\left\{\mathrm{Be} @ p-\mathrm{C}_{2} \mathrm{~B}_{10} \mathrm{H}_{11}\right\}$. The arrows representing dipole moments are not to scale for $(\mathrm{c})$ and $(\mathrm{d})$ since for the latter endohedral complex the dipole moment is $\approx 70$ times larger as compared to the complex from (c)!

network, opens up many opportunities for energy/atom/ion transport via photochemical molecular switches in molecular and nano-photochemistry.

The possibilities of using endohedral boranes and carboranes can be exploited further within nanoscience applications. For instance, the dramatic changes in the dipole moments of the dimeric units displayed in Figure 6, as a function of the position of the endohedral atom, call for potential applications such as molecular condensers or largely orientable molecular devices in electric fields. 


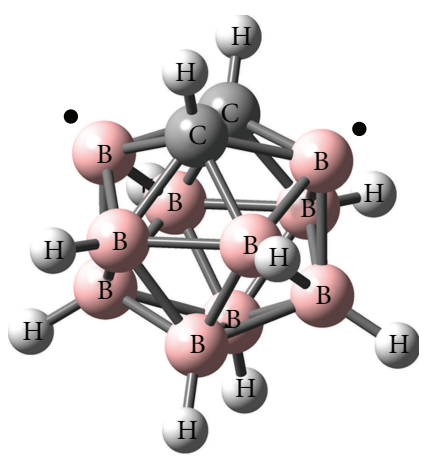

(a)

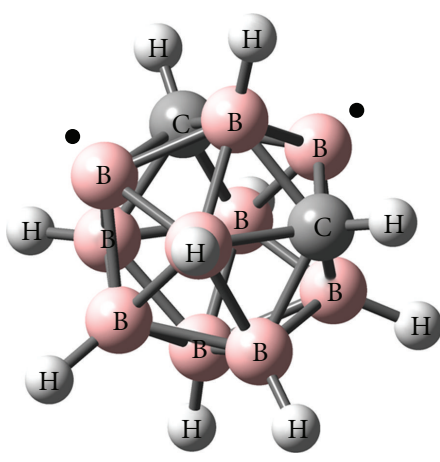

(b)

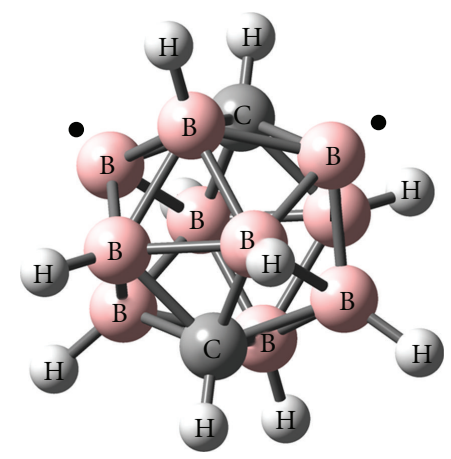

(c)

FIGURE 7: Several examples of carborane single and dimeric biradical with almost degenerate singlet and triplet electronic states. (a) $o$ - $(3,6)$ biradical derived from hydrogen abstraction on positions 3 and 6 in 1,2- $\mathrm{C}_{2} \mathrm{~B}_{10} \mathrm{H}_{12}$ or $o$-carborane: adiabatic singlet-triplet energy gap for this system $\Delta E_{\mathrm{ST}}=0.06 \mathrm{eV}$. (b) $m$ - $(2,4)$ biradical derived from hydrogen abstraction on positions 2 and 4 in $1,7-\mathrm{C}_{2} \mathrm{~B}_{10} \mathrm{H}_{12}$ or $m$-carborane: adiabatic singlet-triplet energy gap for this system $\Delta E_{\mathrm{ST}}=0.04 \mathrm{eV}$. (c) $p$-(2,4) biradical derived from hydrogen abstraction on positions 2 and 4 in 1,12- $\mathrm{C}_{2} \mathrm{~B}_{10} \mathrm{H}_{12}$ or $p$-carborane: adiabatic singlet-triplet energy gap for this system $\Delta E_{\mathrm{ST}}=0.04 \mathrm{eV}$. The dots on each system represent "unpaired" electrons. Geometries and energies are computed with CASSCF and CASPT2 methods, respectively [13].

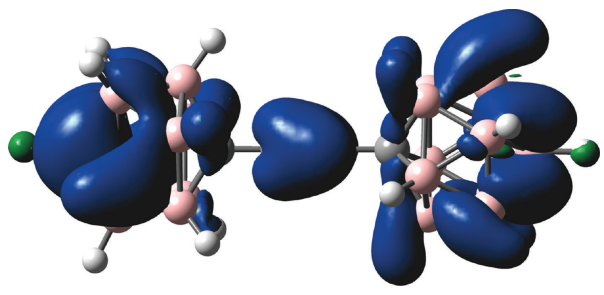

(a)

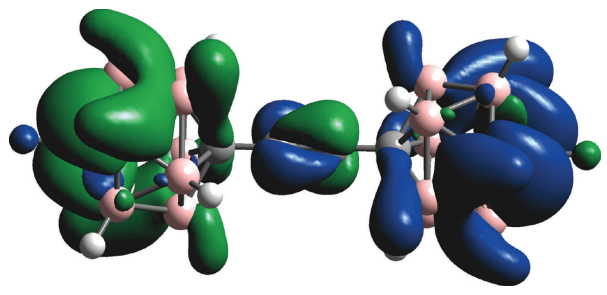

(b)

Figure 8: (a) Spin density $\rho_{s}$ for the triplet state $\left(\left|\rho_{s}\right|= \pm 0.001\right)$. (b) Broken-symmetry singlet biradical spin density $\left(\left|\rho_{s}\right|= \pm 0.001\right)$. UB3LYP/6-31+G(d)//UB3LYP/6-31+G(d) computations. Different colours represent net $\alpha$ and $\beta$ spin density.

These descriptions of (car)boranes from electronic structure computations illustrate the possibilities of changing their properties by the effects of exo substitution-specifically in $o$-carboranes-or by endo insertion/ejection mechanisms. If such endohedral compounds can be prepared, they surely will respond to external perturbations, such as electromagnetic radiation. We are now exploring the consequences of extending systems based on the units considered above in different dimensions. What properties of finite (infinite) aggregates will result? The answer is not straightforward; several theoretical methodologies must be applied.

Biradical systems with nearly degenerate singlet-triplet energy gaps, such as those in Figure 7, are examples of how the properties of single units can change with spin as the parameter. The dimeric system built by joining two $\mathrm{CB}_{11} \mathrm{H}_{12}{ }^{\circ}$ radicals by an acetylene bridge, $\left.{ }^{\circ} \mathrm{HB}\right)_{11}-\mathrm{C} \equiv \mathrm{C}-(\mathrm{BH})_{11}$, illustrates this principle as well. High-level quantum chemical computations showed that this biradical has a singlet ground state with a triplet state very slightly higher in energy $\left(\approx 0.005 \mathrm{eV}\right.$, on the order of $k_{B} \cdot T$ at room temperature)
[15]. Figure 8 shows the spin density of the triplet and the "broken-symmetry" singlet biradical states.

\section{Conclusions}

The properties of borane and carborane clusters can be varied by changing (i) the exo substituents, (ii) the wave function (e.g., singlet versus triplet states), and (iii) the endohedral atoms or ions inserted into monomeric or dimeric units, resulting in very large dipole moments. We also have predicted a theoretical mechanism for atom/ion ejection via a photochemical switch. Our electronic structure computations have established patterns for building higher architectural constructs starting from modified carborane building units. Our goal, to control atom, ion, spin, or energy transport inside borane and carborane networks in different dimensions, aims at the very heart of nanoscience and nanotechnology. The elaboration of higher architectures depends on experimental breakthroughs in assembling molecules, like those begun in the 1990s 


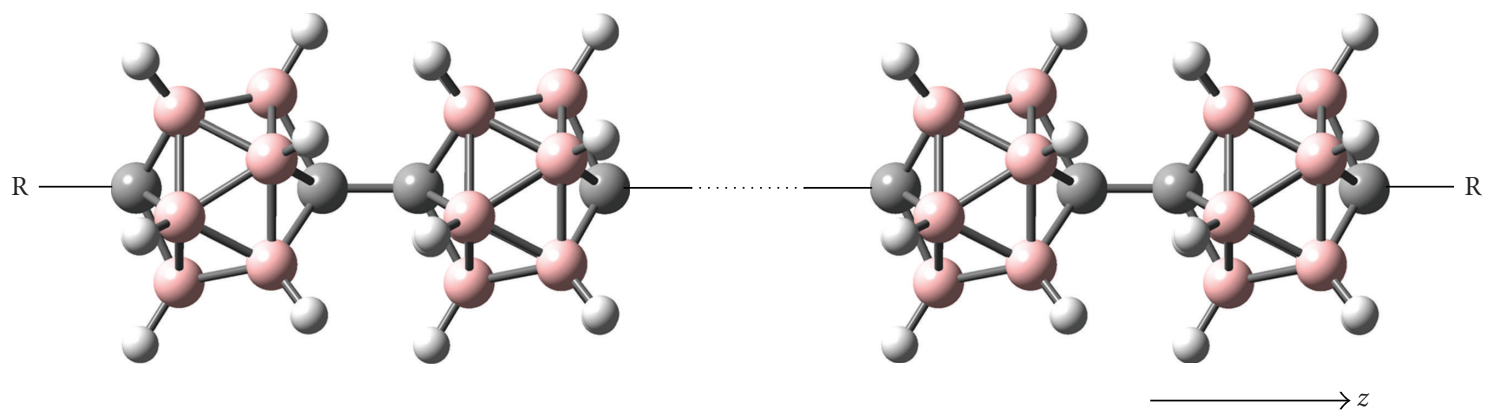

(a)

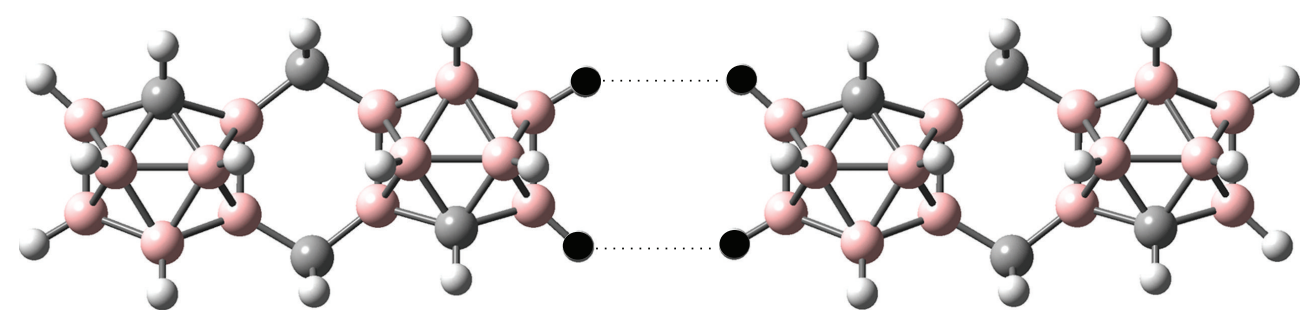

(b)

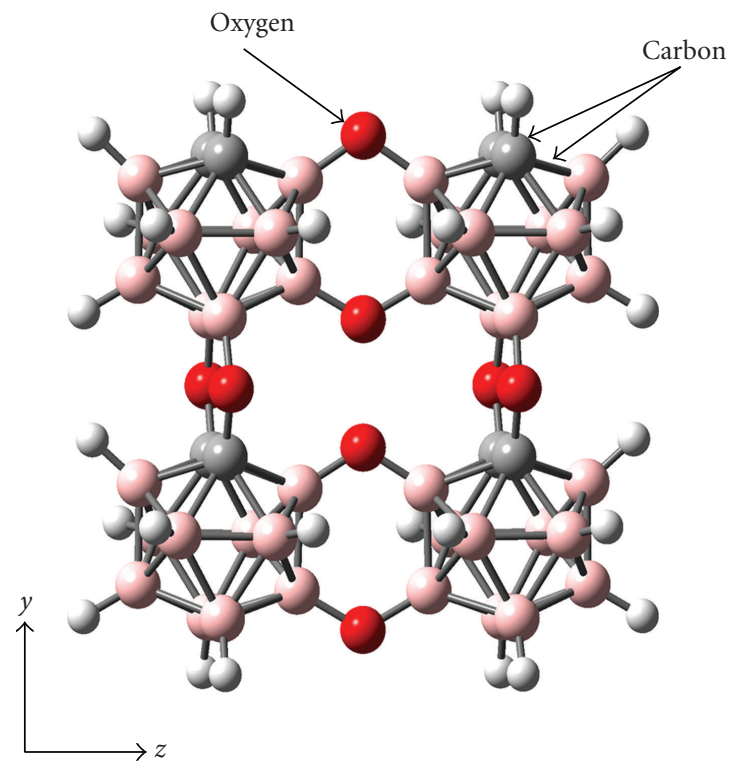

(c)

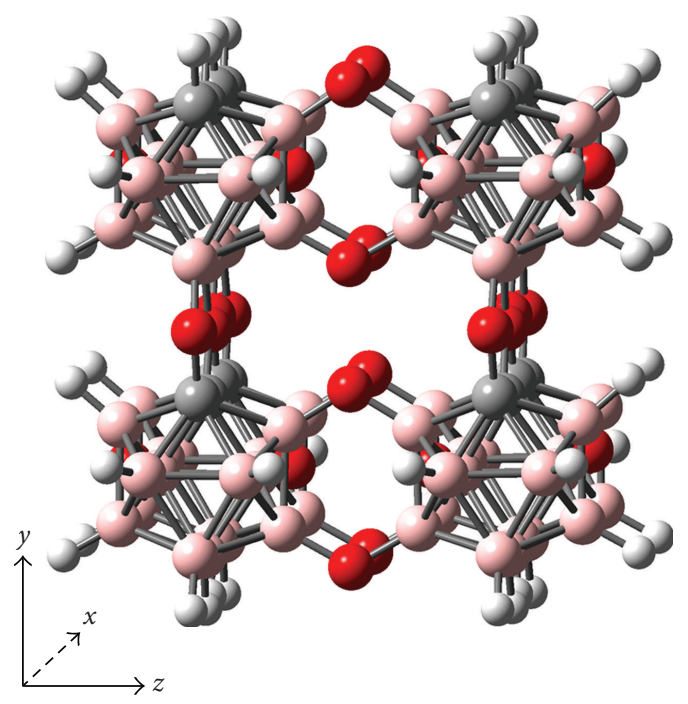

(d)

FIGURE 9: Different higher architectural constructs from $r$-carborane ( $r=$ ortho, meta, para) as building units. (a) A 1D $z$-finite/infinite chain of C-linked para-carborane clusters. (b) A 1D finite/infinite chain of methylene-linked up-down ortho-carborane clusters through two B-H moieties. (c) A " $2 \mathrm{D}$ " neutral finite object, which can be extended to infinity along $y$ and $z$, respectively, creating a $2 \mathrm{D}$ infinite network. (d) A "3D" finite neutral object consisting of H, B, C, and O atoms and forming an oxygen-connected carborane supercluster. The object can be extended to infinity following the $x, y$, and $z$ directions. The geometries in (c) and (d) were optimized with the Hartree-Fock/STO-3G method.

with 1D connections forming linear rods $[18,19]$. Higherdimensional constructs, for example, those in Figure 9, can include endohedral atoms inside the cages. The geometries can be modified by exo substituents. Abstracting hydrogen atoms also would change the properties as the spins of the resulting unpaired electrons might be delocalized in different directions. These possibilities, with the as yet unknown constructs in Figure 8, are research goals and starting points for the elaboration of finite or infinite networks capable of interacting with electromagnetic fields.

\section{Acknowledgments}

This research has been supported by the Spanish MEC/ FEDER, projects MAT2006-13646-C03-02, CTQ2007-61260, 
and CSD2007-0010 Consolider-Ingenio in Molecular Nanoscience, and in the USA by the National Science Foundation Grant CHE-0716718, Georgia, and the Welch Foundation of Houston, Texas, through Grant BD-0894.

\section{References}

[1] F. Teixidor, Ed., "Recent advances in boron chemistry," Journal of Organometallic Chemistry, vol. 694, no. 11, pp. 1587-1780, 2009.

[2] T. B. Marder and Z. Lin, Eds., Contemporary Metal Boron Chemistry I: Borylenes, Boryls, Borane Sigma-Complexes, and Borohydrides, Structure and Bonding, Springer, Berlin, Germany, 2008.

[3] J. M. Oliva and C. Viñas, "Electronic structure and assignment of experimental ${ }^{11} \mathrm{~B}$ nuclei NMR signals in the orthocarborane 1,2-( $\mathrm{SH})_{2}-1,2-\mathrm{C}_{2} \mathrm{~B}_{10} \mathrm{H}_{10}$ by ab initio calculations," Journal of Molecular Structure, vol. 556, no. 1, pp. 33-42, 2000.

[4] C. Viñas, G. Barberà, J. M. Oliva, F. Teixidor, A. J. Welch, and G. M. Rosair, "Are halocarboranes suitable for substitution reactions? The case for 3-I-1,2-closo- $\mathrm{C}_{2} \mathrm{~B}_{10} \mathrm{H}_{11}$ : molecular orbital calculations, aryldehalogenation reactions, ${ }^{11} \mathrm{~B}$ NMR interpretation of closo-carboranes, and molecular structures of 1-Ph-3-Br-1,2-closo- $\mathrm{C}_{2} \mathrm{~B}_{10} \mathrm{H}_{10}$ and 3-Ph-1,2closo- $\mathrm{C}_{2} \mathrm{~B}_{10} \mathrm{H}_{11}$," Inorganic Chemistry, vol. 40, no. 26, pp. 6555-6562, 2001.

[5] J. Llop, C. Viñas, J. M. Oliva, et al., "C obaltabisdicarbollide anion $\left[\mathrm{Co}\left(\mathrm{C}_{2} \mathrm{~B}_{9} \mathrm{H}_{11}\right)_{2}\right]$ - as doping agent on intelligent membranes for ion capture," Journal of Organometallic Chemistry, vol. 657, pp. 232-238, 2002.

[6] J. M. Oliva, F. Teixidor, and C. Viñas, " $\mathrm{C}-\mathrm{C}$ electronic interaction in 1,2-substituted $1,2-\mathrm{C}_{2} \mathrm{~B}_{10} \mathrm{H}_{10}$ ortho-carboranes: to bond or not to bond?" in Conceptual Aspects of Chemical Bonding, abstracts of papers of the American Chemical Society 226th National Meeting: 664-ORGN part 2, September 2003.

[7] F. Teixidor, G. Barberà, A. Vaca, et al., "Are methyl groups electron-donating or electron-withdrawing in boron clusters? Permethylation of o-carborane," Journal of the American Chemical Society, vol. 127, no. 29, pp. 10158-10159, 2005.

[8] J. M. Oliva, N. L. Allan, P. V. R. Schleyer, C. Viñas, and F. Teixidor, "Strikingly long C . . C distances in 1,2-disubstituted ortho-carboranes and their dianions," Journal of the American Chemical Society, vol. 127, pp. 13538-13547, 2005.

[9] J. M. Oliva and L. Serrano-Andrés, "A computational study of the lowest singlet and triplet states of neutral and dianionic 1,2-substituted icosahedral and octahedral o-carboranes," Journal of Computational Chemistry, vol. 27, no. 4, pp. 524535, 2006.

[10] L. Serrano-Andrés and J. M. Oliva, "Photochemical window mechanism for controlled atom release in carborane endohedral boxes: Theoretical evidence," Chemical Physics Letters, vol. 432, no. 1-3, pp. 235-239, 2006.

[11] V. Manero, J. M. Oliva, L. Serrano-Andrés, and D. J. Klein, "What is the limit of atom encapsulation for icosahedral carboranes?" Journal of Chemical Theory and Computation, vol. 3, no. 4, pp. 1399-1404, 2007.

[12] J. I. Burgos, L. Serrano-Andrés, J. M. Oliva, and D. J. Klein, "On the effect of radical character, substitution and atom encapsulation on the volume of icosahedral (car)boranes," Afinidad, vol. 65, no. 533, pp. 32-38, 2008.

[13] L. Serrano-Andrés, D. J. Klein, P. V. R. Schleyer, and J. M. Oliva, "What electronic structures and geometries of carborane mono- and ortho-, meta-, and para-diradicals are preferred?" Journal of Chemical Theory and Computation, vol. 4, no. 8, pp. 1338-1347, 2008.

[14] J. M. Oliva, D. J. Klein, P. V. R. Schleyer, and L. SerranoAndrés, "Design of carborane molecular architectures with electronic structure computations: from endohedral and polyradical systems to multidimensional networks," Pure and Applied Chemistry, vol. 81, no. 4, pp. 719-729, 2009.

[15] J. M. Oliva, L. Serrano-Andrés, Z. Havlas, and J. Michl, “On the electronic structure of a dianion, a radical anion, and a neutral biradical $(\mathrm{HB})_{11} \mathrm{C}-\mathrm{C} \equiv \mathrm{C}-\mathrm{C}(\mathrm{BH})_{11}$ carborane dimer," Journal of Molecular Structure: THEOCHEM, vol. 912, no. 1-3, pp. 13-20, 2009.

[16] O. Crespo, C. Gimeno, A. Laguna, I. Ospino, G. Aullón, and J. M. Oliva, "Organometallic gold complexes of carborane. Theoretical comparative analysis of ortho, meta, and para derivatives and luminescence studies," Dalton Transactions, vol. 19, pp. 3807-3813, 2009.

[17] H. Hiura and T. Kanayama, "Carborane superclusters formed by ion-molecule reactions in an ion trap," Journal of Molecular Structure, vol. 735-736, pp. 367-374, 2005.

[18] W. Jiang, D. E. Harwell, M. D. Mortimer, C. B. Knobler, and M. F. Hawthorne, "Palladium-catalyzed coupling of ethynylated P-carborane derivatives-synthesis and structural characterization of modular ethynylated P-carborane molecules," Inorganic Chemistry, vol. 35, no. 15, pp. 4355-4359, 1996.

[19] J. Müller, K. Baše, T. F. Magnera, and J. Michl, "Rigid-rod oligo-p-carboranes for molecular tinkertoys. An inorganic Langmuir-Blodgett film with a functionalized outer surface," Journal of the American Chemical Society, vol. 114, p. 9721, 1992.

[20] J. Zhang, A. Osgood, Y. Shirai, et al., "Investigating the motion of molecular machines on surfaces by STmml: the nanocar and beyond," in Proceedings of the 7th IEEE Conference on Nanotechnology (NANO '07), pp. 243-246, Hong Kong, August 2007.

[21] J. N. Hohman, P. Zhang, E. I. Morin, et al., "Self-assembly of carboranethiol isomers on Au111: intermolecular interactions determined by molecular dipole orientations," ACS Nano, vol. 3, no. 3, pp. 527-536, 2009.

[22] S. Khatua, J. M. Guerrero, K. Claytor, et al., "Micrometer-scale translation and monitoring of individual nanocars on glass," ACS Nano, vol. 3, no. 2, pp. 351-356, 2009.

[23] J. D. Joannopoulos, S. G. Johnson, J. N. Winn, and R. D. Meade, Photonic Crystals: Molding the Flow of Light, Princeton University Press, Princeton, NJ, USA, 2nd edition, 2008.

[24] S. Sahoo, T. Kontos, J. Furer, et al., "Electric field control of spin transport," Nature Physics, vol. 1, pp. 99-102, 2005.

[25] N. Tombros, C. Jozsa, M. Popinciuc, H. T. Jonkman, and B. J. van Wees, "Electronic spin transport and spin precession in single graphene layers at room temperature," Nature, vol. 448, pp. 571-574, 2007.

[26] B. O. Roos, "Ab initio methods in quantum chemistry," in Advances in Chemical Physics, K. P. Lawley, Ed., vol. 69, pp. 399-445, John Wiley \& Sons, New York, NY, USA, 1987.

[27] M. Merchán and L. Serrano-Andrés, "Ab initio methods for excited states," in Computational Photochemistry, M. Olivucci, Ed., vol. 81, pp. 743-754, Elsevier, Amsterdam, The Netherlands, 2005.

[28] K. Andersson, M. Barysz, A. Bernhardsson, et al., MOLCAS, Version 5.0., Department of Theoretical Chemistry, Lund, Sweden, 2000. 
[29] A. D. Becke, "A new mixing of Hartree-Fock and local densityfunctional theories," The Journal of Chemical Physics, vol. 98, no. 2, pp. 1372-1377, 1993.

[30] J. P. Perdew, M. Ernzerhof, and K. Burke, "Rationale for mixing exact exchange with density functional approximations," Journal of Chemical Physics, vol. 105, p. 9982, 1996.

[31] S. H. Vosko, L. Wilk, and M. Nusair, "Accurate spin-dependent electron liquid correlation energies for local spin density calculations: a critical analysis," Canadian Journal of Physics, vol. 58, pp. 1200-1211, 1980.

[32] M. J. Frisch, G. W. Trucks, H. B. Schlegel, et al., GAUSSIAN 03, Gaussian, Wallingford, Conn, USA, 2004.

[33] L. Noodleman, C. Y. Peng, D. A. Case, and J. M. Mouesca, "Orbital interactions, electron delocalization, and spin interactions in iron-sulfur clusters," Chemical Reviews, vol. 144, pp. 199-244, 1995.

[34] A. Ovchinnikov and J. K. Labanowski, "Simple spin correction of unrestricted density-functional calculation," Physical Review A, vol. 53, no. 6, pp. 3946-3952, 1996.

[35] K. Yamaguchi, T. Kawasaki, Y. Takano, Y. Kigarawa, Y. Yamashita, and H. Fujita, "Electronic excitations and first hyperpolarizability of 2-methyl-4-nitroaniline clusters," International Journal of Quantum Chemistry, vol. 90, pp. 359-370, 2002.

[36] R. N. Grimes, Carboranes, Academic Press, New York, NY, USA, 1970.

[37] X. Yang, W. Jiang, C. B. Knobler, and M. F. Hawthorne, "Chemical structures and schematic representations of a crown ether," Journal of the American Chemical Society, vol. 114, p. 9719, 1992.

[38] B. T. King, S. Korbe, P. J. Schreiber, et al., "The sixteen $\mathrm{CB}_{11} \mathrm{H}_{n} \mathrm{Me}_{12-n}$ anions with fivefold substitution symmetry: anodic oxidation and electronic structure," Journal of the American Chemical Society, vol. 129, no. 43, pp. 12960-12980, 2007.

[39] B. T. King, B. C. Noll, A. J. McKinley, and J. Michl, "Dodecamethylcarba-closo-dodecaboranyl $(\mathrm{CB}(11) \mathrm{Me}(12)()$.$) , a$ stable free-radical," Journal of the American Chemical Society, vol. 118, no. 44, pp. 10902-10903, 1996.

[40] L. Eriksson, K. Vyakaranam, J. Ludvik, and J. Michl, "Synthesis of the isolable biradicals $\cdot\left(\mathrm{CH}_{3} \mathrm{~B}\right)_{11} \mathrm{C}-\mathrm{C} \equiv \mathrm{C}-\mathrm{C}\left(\mathrm{BCH}_{3}\right)_{11} \cdot$ and trans- $\cdot\left(\mathrm{CH}_{3} \mathrm{~B}\right)_{11} \mathrm{C}-\mathrm{CH}=\mathrm{CH}-\mathrm{C}\left(\mathrm{BCH}_{3}\right)_{11} \cdot$," The Journal of Organic Chemistry, vol. 72, no. 7, pp. 2351-2356, 2007.

[41] I. Zharov, A. Saxena, J. Michl, and J. Miller, "C-hydroxy-closododecaboranes," Inorganic Chemistry, vol. 36, p. 6033, 1997.

[42] J. Michl and V. Bonacic-Koutecky, Electronic Aspects of Organic Photochemistry, Wiley-Interscience, New York, NY, USA, 1990.

[43] E. D. Jemmis and M. M. Balakrishnarajan, "Ab initio predictions on novel stuffed polyhedral boranes," Journal of the American Chemical Society, vol. 122, no. 30, pp. 7392-7393, 2000.

[44] O. P. Charkin, N. M. Klimenko, D. Moran, A. M. Mebel, D. O. Charkin, and P. V. R. Schleyer, "Theoretical study of complexes of closo-borane, alane, and gallane anions with cations of light metals inside and outside of icosahedral clusters $\left[\mathrm{A}_{12} \mathrm{H}_{12}\right]$ $(\mathrm{A}=\mathrm{B}, \mathrm{Al}$, and Ga)," Journal of Physical Chemistry A, vol. 106, no. 47, pp. 11594-11602, 2002. 


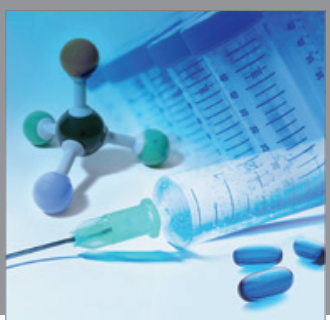

International Journal of

Medicinal Chemistry

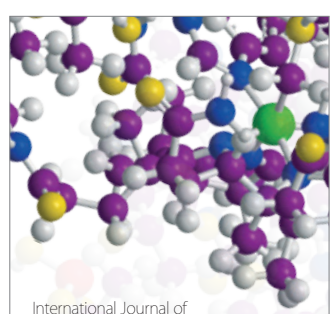

Carbohydrate Chemistry

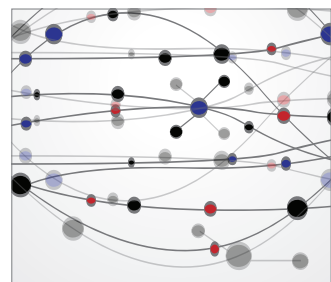

The Scientific World Journal
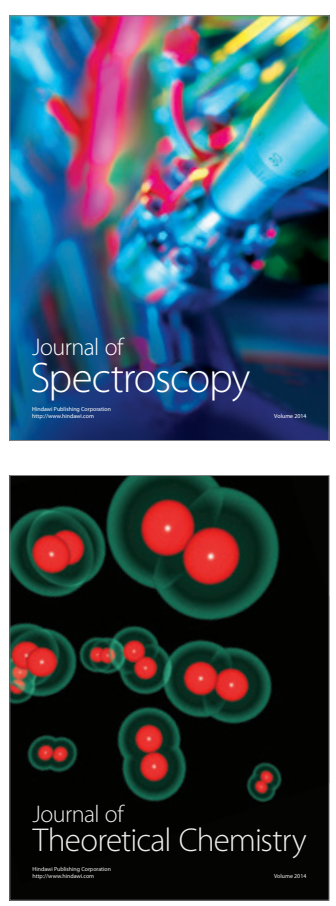
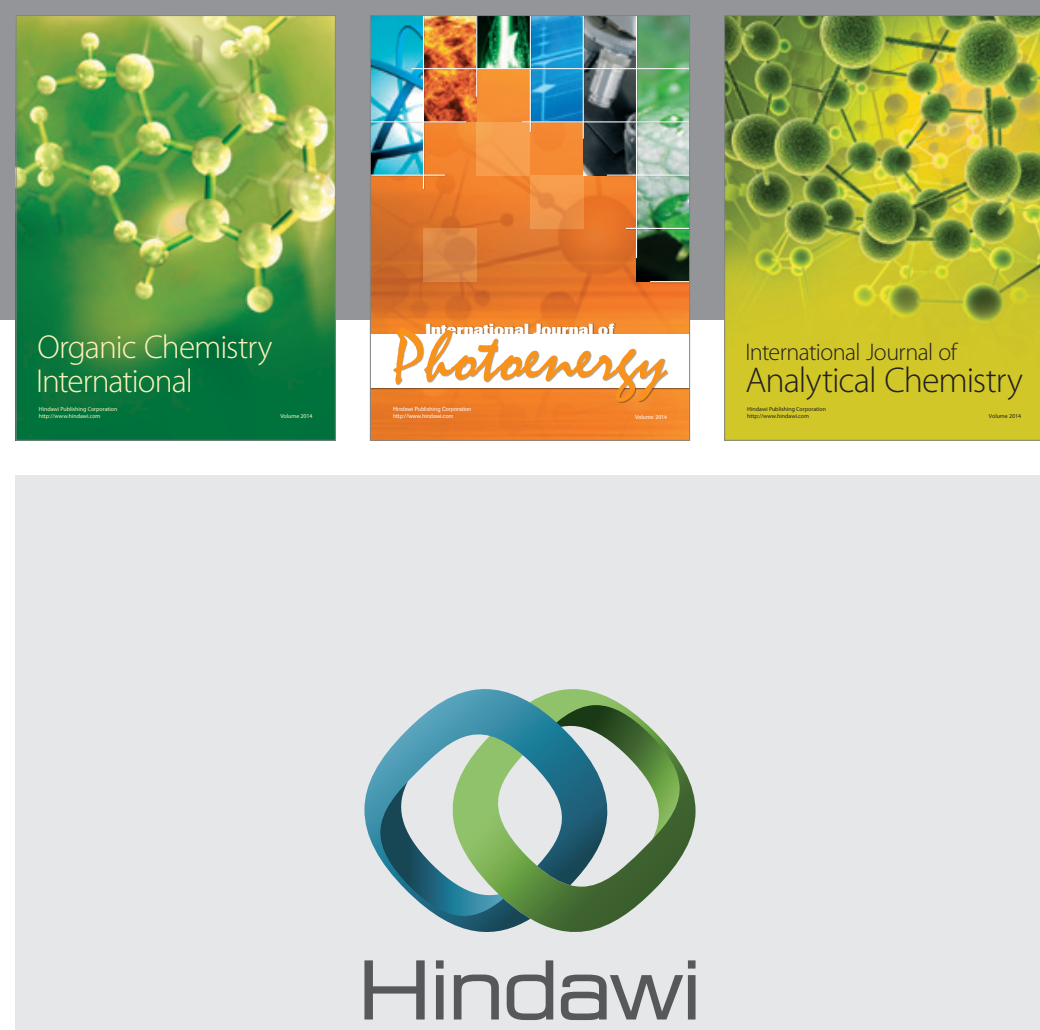

Submit your manuscripts at

http://www.hindawi.com
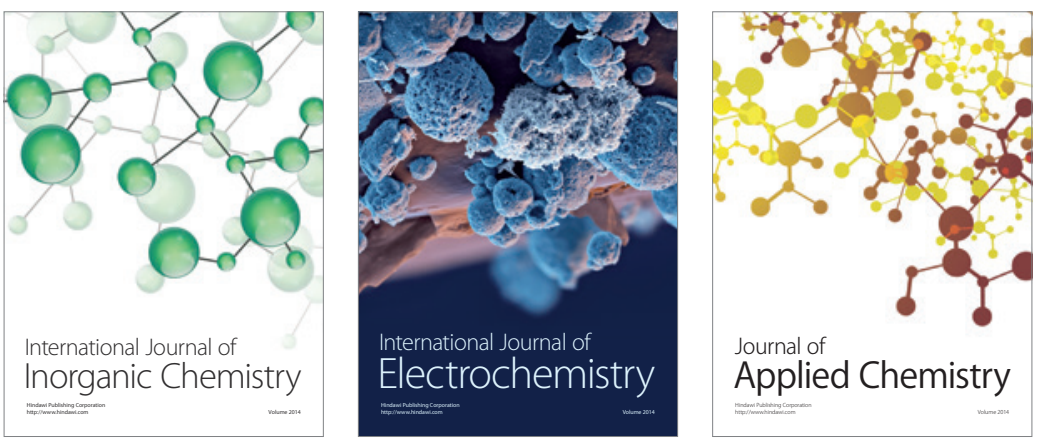

Journal of

Applied Chemistry
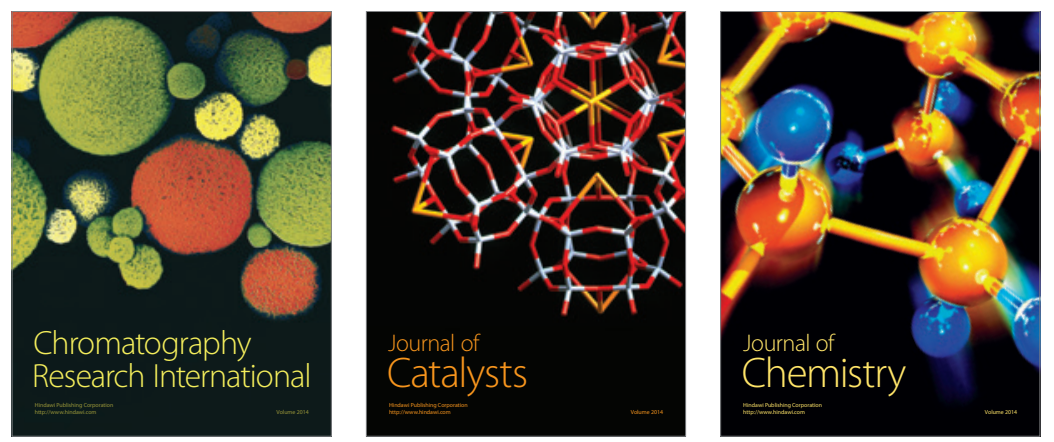
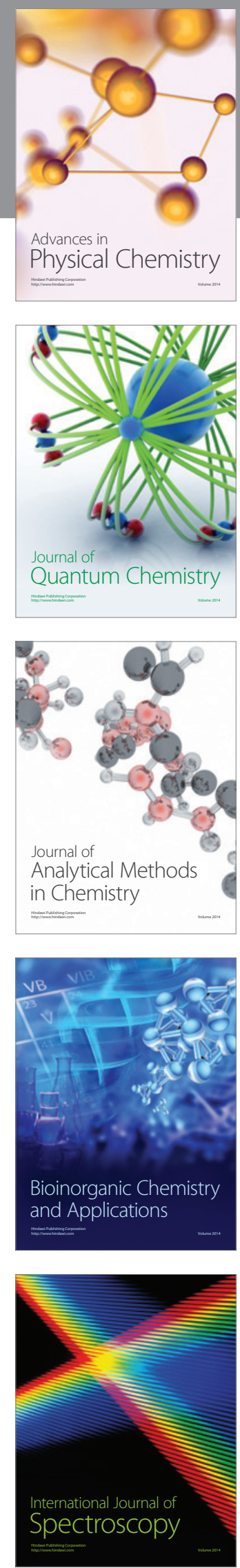